\title{
MIELOPATIA POR DEFICIÊNCIA DE VITAMINA B12 APRESENTANDO-SE COMO MIELITE TRANSVERSA
}

\author{
Luiz Felipe Rocha Vasconcellos' ${ }^{1}$, Rosalie Branco Corrêa', Leila Chimelli", \\ Fernanda Nascimento ${ }^{4}$, Adriane Baptista Fonseca ${ }^{5}$, Janaina Nage/, \\ Sergio Augusto Pereira Novis ${ }^{7}$, Maurice Vincent ${ }^{8}$
}

\begin{abstract}
RESUMO - As manifestações neurológicas associadas à deficiência de vitamina B12 incluem polineuropatia, mielopatia, demência e neuropatia óptica. 0 diagnóstico laboratorial é feito através da dosagem sérica de cianocobalamina ou homocisteína e da excreção urinária de ácido metilmalônico. No estudo anatomopatológico observa-se na microscopia a destruição da mielina e de axônios vistos na substância branca. A região mais comumente afetada é o cordão posterior cervical e/ou torácico. 0 acometimento da coluna lateral é raro, ocorrendo em casos graves e avançados. O tratamento consiste na reposição de vitamina B12 e a resposta depende da gravidade do quadro e do tempo transcorrido entre o inicio dos sintomas e inicio do tratamento. Relatamos o caso de um paciente que apresentou, como manifestação de deficiência de vitamina B12, mielite transversa. $O$ estudo morfológico da medula demonstrou comprometimento dos tractos cortico-espinhais lateral e anterior, da coluna dorsal e ainda do tracto espino-talâmico.
\end{abstract}

PALAVRAS-CHAVE: mielite transversa, vitamina B12, anemia perniciosa.

\section{Myelopathy due to vitamin B12 deficiency presenting as transverse myelitis}

ABSTRACT - Vitamin B12 deficiency may induce neuropathy, myelopathy, dementia and optic neuropathy. The diagnosis is established by vitamin B12, homocysteine and methylmalonic acid measurements. Myelin and axon destruction in the white matter of the spinal cord are observed. The posterior column of the cervical and thoracic level is the most common involved area. The involvement of the anterior column is restricted to advanced and relatively severe cases. Treatment is based on vitamin B12 injections, and the prognosis depends on the stage of vitamin deficiency and deterioration at treatment onset. We report a case with transverse myelitis due to vitamin B12 deficiency. This picture is relatively uncommon, however, we believe patients with transverse myelitis should have vitamin B12 studies as part of the diagnosis work up.

KEY WORDS: transverse myelitis, vitamin B12, pernicious anemia.

A mielopatia por deficiência de vitamina B12 manifesta-se inicialmente por parestesias e fraqueza, comprometendo os quatro membros num padrão simétrico. Nas fases avançadas, ocorre paraplegia e graus variados de espasticidade. A ocorrência de nível sensitivo raramente é observada'. O diagnóstico laboratorial inicial baseia-se na dosagem sérica de vitamina B12, que na maioria dos casos se encontra diminuída².O tratamento consiste na reposição parenteral de vitamina $\mathrm{B} 12$. A resposta ao tratamento está relacionada à gravidade do quadro e tempo entre o início dos sintomas e tratamento ${ }^{1}$
Apresentamos o caso de um paciente com quadro de mielite transversa secundária a deficiência de vitamina B12.

\section{CASO}

Homem, 49 anos, com diabetes mellitus tipo 2 e hipotireoidismo decorrente de tireoidectomia por doença de Graves, com história familiar de anemia perniciosa. Iniciou sintomas neurológicos há um ano caracterizados por quadro progressivo de parestesias nos quatro membros, paraplegia flácida e arreflexa, anestesia completa abaixo de T8 e incontinência urinária e fecal.

\footnotetext{
${ }^{1}$ Residente em Neurologia do Instituto de Neurologia Deolindo Couto (INDC)- Universidade Federal do Rio de Janeiro (UFR), Rio de Janeiro RJ, Brasil; ${ }^{2}$ Médica Neurologista do Serviço de Neurologia do Hospital Universitário Clementino Fraga Filho (HUCFF) da UFRJ; ${ }^{3}$ Professora Titular de Anatomia Patológica da Faculdade de Medicina da UFRJ; ${ }^{4}$ Residente em Neurocirurgia do HUCFF-UFRJ, ${ }^{5}$ Residente em Neuropediatria do Instituto Fernandes Figueira (IFF), ${ }^{6}$ Residente em Patologia do HUCFF-UFRJ, ${ }^{7}$ Professor Titular de Neurologia da Faculdade de Medicina da UFRJ; ${ }^{8}$ Chefe do Serviço de Neurologia do HUCFF-UFRJ.
}

Recebido 25 Junho 2001, recebido na forma final 27 Agosto 2001. Aceito 17 Setembro 2001. 
O exame do líquido cefalorraquidiano (LCR) e a ressonância magnética (RM) foram normais. A eletroneuromiografia (ENMG) evidenciou polineuropatia de padrão axonal nos membros inferiores. Sorologias para HIV, HTLVI, HbsAg e VDRL foram negativas e o anti-HCV foi positivo. O hemograma mostrou anemia megaloblástica. A dosagem de vitamina B12 foi menor que $50 \mathrm{pg} / \mathrm{ml}$ (deficiência grave). $O$ anticorpo antifator intrínseco foi positivo e a biópsia de corpo gástrico demonstrou gastrite atrófica, compatível com diagnóstico de deficiência de vitamina B12 por anemia perniciosa.

O quadro neurológico não se modificou apesar da melhora da anemia megaloblástica com reposição parenteral de cianocobalamina, havendo normalização do VGM. Evoluiu com infecção respiratória e óbito após 3 meses de internação.

Foi realizada necropsia e o estudo morfológico da medula espinhal demonstrou quadro de esclerose combinada da medula envolvendo todos os níveis, sobretudo o segmento torácico, onde a degeneração mielino-axonal era muito grave e se estendia às raízes e gânglios sensitivos (Figs 1 e 2).

Além dos tratos córtico-espinhais laterais e anterior e da coluna dorsal, classicamente envolvidos nessa mielopatia, havia também degeneração do tracto espino-talâmico, justificando o nível sensitivo (Fig. 3).

\section{DISCUSSÃO}

A deficiência de vitamina B 12 pode levar a alterações hematológicas, neurológicas, psiquiátricas e gastrintestinais ${ }^{3}$. As causas incluem anemia perniciosa, doença de Crohn e Whipple, gastrectomia parcial, esprue, esclerodermia, alcoolismo, hipertireoidismo, anemias hemolíticas, alimentação exclusivamente vegetariana, linfoma, exposição a óxido nítrico, HIV, sendo que a causa mais frequente é anemia perniciosa $^{4}$. A anemia perniciosa decorre da ausência do fator intrínseco que é uma proteína secretada pelas células parietais necessária para a absorção de vitamina B12. No caso apresentado foi comprovada tal etiologia através de biópsia gástrica e dosagem de anticorpo antifator intrínseco.

A deficiência de vitamina B12 pode ainda ocorrer em alguns pacientes com esclerose múltipla (EM). Há alteração no metabolismo desta vitamina nestes pacientes, de causa ainda não esclarecida ${ }^{5}$. Reynolds et al. ${ }^{5}$ preconizam a dosagem de cianocobalamina nos pacientes com EM, pois quando coexiste esta deficiência pode haver agravamento do quadro, sendo esta uma causa tratável. Outra forma de apresentação que já foi associada à deficiência de vitamina B12, é a de oftalmoplegia internuclear. Assis e Fonseca ${ }^{6}$ relataram o caso de uma paciente com quadro de mielopatia e neuropatia associado a oftalmoplegia internuclear decorrente de mielose funicular. A etiologia foi comprovada através da prova de Schilling que demonstrou diminuição da absorção da vitamina B12 radioativa marcada por

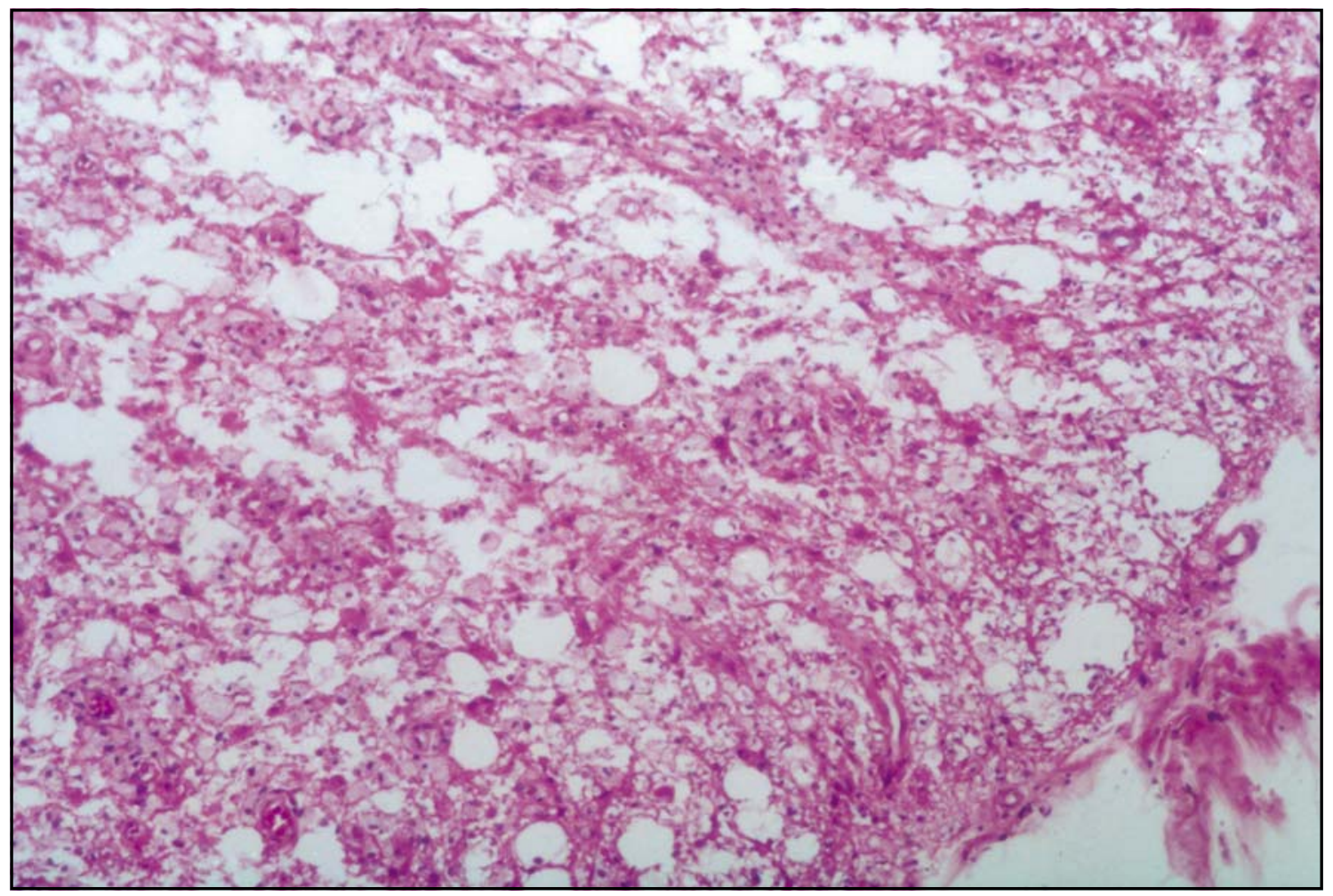

Fig 1. Degeneração do tracto cortico-espinhal com aspecto vacuolizado. $H$ \& $E$. 


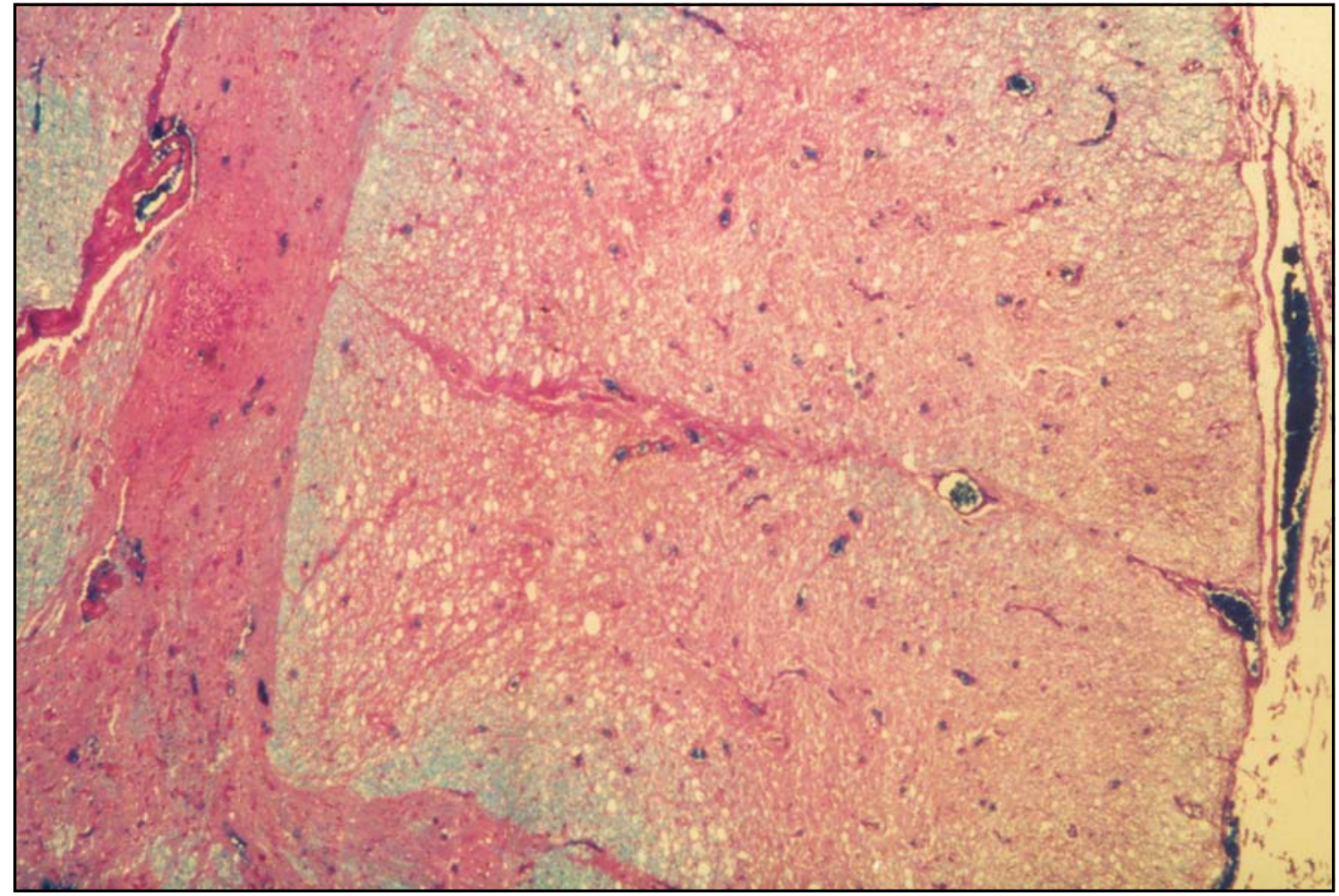

Fig 2. Degeneração da coluna dorsal e perda mielino- axonal. Luxol fast blue.

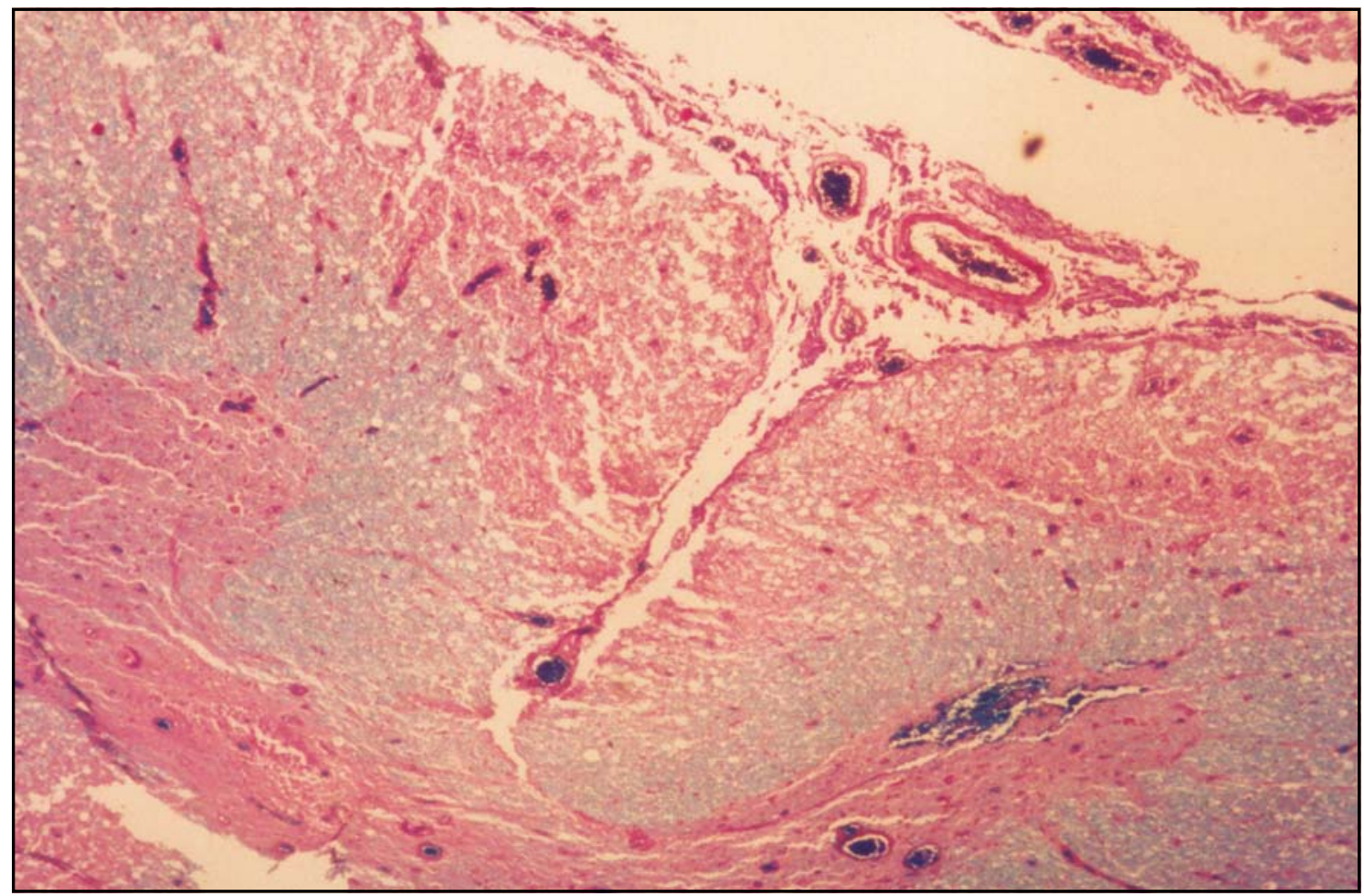

Fig 3. Degeneração do tracto córtico-espinhal anterior e parte do espino-talâmico anterior. Luxol fast blue. 
cobalto. A ENMG descartou lesão neurogênica ou miopática ${ }^{6}$.

O óxido nítrico, usado em anestesias, pode ser fator desencadeante de degeneração subaguda combinada em pacientes com deficiência de vitamina B12 assintomáticos ${ }^{7}$. Pacientes submetidos a cirurgias e que desenvolvem após dias ou semanas quadro de mielopatia, neuropatia sensitiva, alterações da sensibilidade profunda e encefalopatia associados ou não, devem ser investigados para uma possível deficiência de vitamina B12 7 .

Os sintomas neurológicos compreendem deficiências motoras simétricas com graus variados de espasticidade associados à hiper ou hiporreflexia, ataxia, parestesias, alterações da sensibilidade profunda, alterações cognitivas, distúrbios esfincterianos, diminuição da acuidade visual'. A paraparesia ou tetraparesia decorre de um comprometimento das vias piramidais associando-se em geral a hipopalestesia e/ou abatiestesia dos membros, por comprometimento cordonal posterior. As parestesias ocorrem devido a polineuropatia, que na maioria das vezes tem padrão axonal. O quadro cognitivo caracterizase por síndrome demencial de padrão subcortical, sendo uma das causas tratáveis de demência ${ }^{4}$. A deficiência de vitamina B12 pode raramente levar a alterações visuais que ocorrem devido à atrofia óptica. Canelas ${ }^{8}$, em estudo com 110 casos de mielose funicular, observou os seguintes achados ao exame físico: apalestesia $(96,4 \%)$; distúrbio da sensibilidade postural (65,7\%); ataxia apendicular $(74,5 \%)$; sinal de Romberg (83,2\%); sinal de Babinski $(46,5 \%)$ e distúbios esfincterianos $(24 \%)^{8}$.

A presença de nível sensitivo como apresentado por nosso paciente é raramente observada. Há poucos casos relatados de mielite transversa por deficiência de cianocobalamina. Kosik et al. ${ }^{9}$ relataram o caso de uma mulher de 23 anos com diagnóstico de anemia perniciosa que desenvolveu um quadro de mielite transversa com nível em T10 de instalação aguda devido à deficiência de vitamina B12. A presença de nível sensitivo denota quadro grave de deficiência de vitamina B12 e pode ser considerado um achado associado a mau prognóstico. No caso apresentado, o paciente apresentava paraplegia flácida e arreflexa com nível sensitivo, demonstrando assim prognóstico reservado em relação à resposta terapêutica, como ficou comprovado pelo quadro inalterado após reposição de cianocobalamina.

O diagnóstico laboratorial é feito através da dosagem sérica de vitamina B12 ou homocisteína e do ácido metilmalônico na urina. A dosagem de vitamina B12 tem sensibilidade e especificidade limitadas. Apesar de ser infrequente pode-se ter deficiência de vitamina B12 com nível sérico normal ou até aumentado ${ }^{10}$. A hepatopatia, por exemplo, pode aumentar os níveis das proteínas transportadoras (transcobalaminas I e III) com consequente aumento do nível sérico de cianocobalamina ${ }^{11}$. A dosagem de homocisteína e ácido metilmalônico tem melhor sensibilidade e especificidade que a cianocobalamina ${ }^{13}$. Stabler et al. ${ }^{12}$ realizaram estudo em uma população idosa e demonstraram que até $15 \%$ desta população apresentava deficiência de vitamina B12, e todos aqueles casos com significado clínico apresentavam hiperhomocisteinemia concomitante.

No hemograma observa-se anemia e menos comumente leucopenia, além de plaquetopenia. A anemia megaloblástica está presente na maioria dos casos sendo que em até $1 / 3$ dos casos pode estar ausente. Healton et al. ${ }^{2}$ em estudo realizado com 143 pacientes que apresentavam deficiência de vitamina B12, observaram que em $27,4 \%$ o hematócrito era normal e $23 \%$ apresentavam VGM normal. A biópsia de medula óssea é, em geral, hiperplásica, com predomínio de precursores eritrocitários ${ }^{11}$. 0 paciente relatado apresentava anemia com VGM elevado, sendo estes achados os mais freqüentes de acordo com a literatura pesquisada. No presente caso houve normalização do VGM com o tratamento. A dosagem do anticorpo antifator intrínseco é positiva nos casos de anemia perniciosa, como no caso relatado.

A ENMG nos casos de polineuropatia revela, em geral, diminuição ou ausência dos potenciais de ação sensitivos e velocidade de condução normal ${ }^{11}$.

A RM pode mostrar áreas de desmielinização no cérebro ou medula correspondendo a áreas de hiperintensidade na sequência ponderada em T2. Este achado é mais comumente encontrado no cordão posterior da medula. Silva et al. ${ }^{14}$ relataram o caso de uma paciente com paraparesia associada a piramidalismo e perda da noção de posição segmentar, que apresentava RM de medula espinhal normal e de encéfalo com áreas de desmielinização (feixe piramidal bilateralmente), demonstrando que os achados de imagem podem estar restritos ao encéfalo em pacientes paraparéticos ${ }^{14}$. As alterações radiológicas podem levar até 12 meses para desaparecer ${ }^{3}$. No caso relatado foi feito estudo radiológico através de RM da medula espinhal e do encéfalo não sendo evidenciadas alterações da substância branca, apesar da gravidade do quadro.

A terapêutica baseia-se na reposição parenteral de cianocobalamina ${ }^{11}$. Alguns esquemas são propos- 
tos, como por exemplo $1000 \mathrm{mg}$ IM duas vezes por semana, por duas semanas, seguido de uma dose semanal por 3 meses e uma dose mensal após este período. A recuperação torna-se evidente após 3 a 6 meses de tratamento; após este período a recuperação é lenta podendo durar até anos ${ }^{1}$.

Em conclusão, a apresentação medular da deficiência de vitamina B12 sob a forma de mielite transversa é rara devendo contudo ser considerada tal etiologia nesta situação. A presença do nível sensitivo é explicada pelo comprometimento do trato espino-talâmico como observado no caso relatado. A causa mais comumente implicada nesta deficiência, de acordo com a literatura pesquisada, é a anemia perniciosa. Um fator genético tem sido implicado em alguns casos de anemia perniciosa com várias gerações acometidas, como o aqui apresentado ${ }^{15}$. Trata-se de uma doença tratável que, se diagnosticada precocemente, apresenta bom prognóstico. Nosso paciente apresentava deficiência grave e sintomas neurológicos há 1 ano, o que poderia explicar a não reversão do quadro neurológico. Apresentava ainda nível sensitivo, que pode ser considerado um fator de mau prognóstico nos casos de mielopatia por deficiência de vitamina B12.

\section{REFERÊNCIAS}

1. Adams R, Victor M. Principles of neurology. 6.Ed. New York: McGrawHill, 1997:1138-1165.

2. Heaton EB, Savage DG, Brust JC, Garret TJ, Lindenbaum J. Neurologic aspects of cobalamin deficiency. Medicine 1991;70:229-245.

3. Hemmer B, Glocker FX, Schumacher M, Deuschl G, Lucking CH. Subacute combined degeneration: clinical, electrophysiological and magnetic resonance imaging findings. J Neurol Neurosurg Psychiatry 1998;65:822-827.

4. Capdevilla AM, Gorjón E, Romero, J, Moreno MA, Escriche D. Degeneratión combinada subaguda sin anemia. Rev Neurol 2000; 30:797.

5. Reynolds EH, Bottiglieri FR, Laundy M, Crelin RF, Kirker SG. Vitamin B12 metabolism in multiple sclerosis. Arch Neurol 1992;49:649-652.

6. Assis JL, Fonseca LC. Oftalmoplegia internuclear em paciente com mielose funicular. Arq Neuropsiquiatr 1968;26:160-164.

7. Marié RM, Biez 1, Eric Busson P, et al. Nitrous oxide anesthesia associated myelopathy. Arch Neurol 2000;57:380-382.

8. Canelas HM. Mieloses funiculares: considerações a propósito de 110 casos. Arq Neuropsiquiatr 1960;18:105-130.

9. Kosik KS, Mullins TF, Bradley WG, Tempelis LD, Cretella AJ. Coma and axonal degeneration in vitamin B12 deficiency. Arch Neurol 1980;37:590-592.

10. Reynolds EH, Bottiglieri FR, et al. Subacute combined degeneration with high serum vitamin B12 level and abnormal vitamin B12 binding protein. Arch Neurol 1993;50:739-743.

11. Bradley WG, Daroff R, Fenichel G, Marsden CD. Neurology in clinical practice. 3.Ed. Boston: Butterworth Heinemann, 2000:1495-1509.

12. Stabler S. Vitamin B12 deficiency in elderly: current dilemmas. American J Clinical Nutrition 1997;66:741-749.

13. Savage D, Lindenbaun J, Stabler S, Allen R. Sensitivity of serum methylmalonic acid and total homocisteine determination for diagnosis cobalamin and folate deficiencies. Am J Med 1994;96:239-246.

14. Silva MTT, Cavalcanti JLS, Moreira DM. Alterações neurorradiológicas cerebrais na degeneração combinada de medula. Arq Neuropsiquiatr 2000;58:752-755.

15. Toh BH, Driel IR, Gleeson PA. Mechanisms of disease: pernicious anemia. N Engl J Med 1997;337:1441-1448. 